\title{
Research Progress of Gaseous Polycyclic Aromatic Hydrocarbons Purification by Adsorption
}

\author{
Xiong Yang ${ }^{1,2}$, Ziyi $\mathrm{Li}^{1,2^{*}}$, Yingshu Liu ${ }^{1,2}$, Yi Xing ${ }^{1,2}$, Jinchao Wei ${ }^{3}$, Bentao Yang ${ }^{3}$, \\ Chuanzhao Zhang ${ }^{4}$, Ralph T. Yang ${ }^{5}$, Chuen-Jinn Tsai ${ }^{6}$ \\ ${ }^{1}$ School of Energy and Environmental Engineering, University of Science and Technology Beijing, Beijing 100083, China \\ ${ }^{2}$ Beijing Higher Institution Engineering Research Center of Energy Conservation and Environmental Protection, Beijing \\ 100083, China \\ ${ }^{3}$ Zhongye Changtian International Engineering Co., Ltd., Changsha 410205, China \\ ${ }^{4}$ College of Biochemical Engineering, Beijing Union University, Beijing 100023, China \\ ${ }^{5}$ Department of Chemical Engineering, University of Michigan, Ann Arbor, MI 48109, USA \\ ${ }^{6}$ Institute of Environmental Engineering, National Chiao Tung University, Hsinchu 30010, Taiwan
}

\begin{abstract}
Gaseous polycyclic aromatic hydrocarbons (PAHs) are carcinogenic and mutagenic pollutants and also able to promote the growth of secondary particulate matters, which have attracted great attention in recent years. Control of PAHs emissions in exhaust gases using different techniques has been hot topics in the atmospheric environment field. Adsorption is one of the most effective ones and is well accepted by industries in gaseous pollutant removal in which the adsorbent characteristics play critical roles. In this paper, the latest advances in the field of PAHs adsorption are critically reviewed with special emphasis on adsorption-desorption characteristics and related applications. Studies on adsorption equilibrium, kinetics, and desorption properties of PAHs as special low-volatile gases on conventional activated carbons and novel mesoporous adsorbents are summarized and compared, showing the advantages of mesoporous adsorbents over traditional adsorbents in terms of the fast adsorption and facile desorption. The significant factors on the optimal balance between adsorption and desorption as well as the corresponding adsorbent materials are discussed in detail. This work can be a reference for further studies on adsorptive purifications of PAHs and other low-volatile gases.
\end{abstract}

Keywords: Polycyclic aromatic hydrocarbons; Low volatility; Adsorption; Desorption; Adsorbents.

\section{INTRODUCTION}

Polycyclic aromatic hydrocarbons (PAHs, also polyaromatic hydrocarbons or polynuclear aromatic hydrocarbons) are hydrocarbons-organic compounds containing only carbon and hydrogen - that are composed of multiple aromatic rings (organic rings in which the electrons are delocalized). They are the earliest discovered and most abundant types of carcinogens (Villemin et al., 1994). PAHs have characteristics of high boiling point, large molecular weight and low vapor pressure. The number of aromatic rings and molecular weight are important factors affecting their physical and chemical properties. Most of the PAHs that have been discovered so far are highly toxic, and some PAHs metabolites or derivatives are potential

\footnotetext{
* Corresponding author.

Tel.: +861062334210

E-mail address: ziyili@ustb.edu.cn
}

mutagens (Dat et al., 2018). In 1976, the EPA's list of 129 "priority pollutants" included 16 kinds of PAHs compounds (Keith and Telliard, 1979).

Sources of PAHs mainly include natural sources and man-made sources. Natural effects such as forest fires, volcanic eruptions, and biosynthesis produce small amounts of PAHs (Sugiyama et al., 2017), while with the rapid development of human production and life, man-made sources contribute to greater amounts of PAHs emissions including: (1) incomplete combustion or reduction of various fossil fuels (such as petroleum, coal) and other hydrocarbons; (2) chemical industry, organic chemical raw material industry, chemical raw material manufacturing and other industries; (3) coking industrial production enterprises coking, petroleum cracking, coal tar refining and other processes; (4) trash and waste incinerators (Wang et al., 2002, 2009). There is an increasing concern about the occurrence of PAHs as carcinogens, mutagens, teratogens and bioaccumulation since they are ubiquitous in ambient air, airborne particulate matter (Lovet et al., 2018; Zhang et al., 2018) and have great damage on environmental and 
human beings (Cheng et al., 2004; Yang et al., 2008; Owabor et al., 2010; Long et al., 2017).

Controlling PAHs emissions has become a hot topic in the field of atmospheric environment research. Previous researches on purifying gaseous PAHs can be classified into two types, the destructive technologies such as photocatalytic degradation (Zhang et al., 2008), plasma (Yu et al., 2010) and catalytic oxidation (Shie et al., 2005), and the recoverable technologies such as adsorption, absorption, condensation and membrane separation. Among them, adsorption is considered to be one of the most promising PAHs purification methods because of its cost-effectiveness, simple operation and high removal efficiency at low concentrations (Liu et al., 2002; McKay et al., 2002; Tseng et al., 2002; Ghafari and Atkinson, 2018). The characteristics of adsorbents and an appropriate selection of the materials play critical roles in practical use of adsorption purification technologies. The high adsorption capacity, fast adsorption rate and low regeneration energy consumption are commonly the targeted characteristics that an ideal adsorbent should process.

In comparison to ordinary gases, gaseous PAHs with larger molecular weights and low volatilities render different adsorption characteristics, for instance, the stronger affinity on the pore surfaces and thus the significant adsorption capacity at very low concentrations. However, the larger molecular sizes of PAHs are not conducive to adsorption diffusion and mass transfer inside the pores of adsorbents, and therefore greatly reduce the adsorption rate. Besides, due to the strong interactions between PAHs and adsorbents, a much higher thermal desorption temperature for adsorbent regeneration would be required, which causes higher energy consumption in temperature swing adsorption processes in practical applications. Therefore, the exploration of the optimal balance between PAHs adsorption and desorption has become one of the core research content of PAHs adsorption purification. Activated carbons as a type of adsorbents are widely accepted in industry due to the low price and great PAHs adsorption capacity, and need high desorption temperatures and higher regeneration energy consumption due to the rich microporosity. With the rapid development of mesoporous materials in recent years, adsorptive removal of PAHs based on ordered mesoporous adsorbents has gradually entered scholar's vision, which could be a replacement for activated carbons and has potentials of solving corresponding practical problems. Mesoporous materials not only have large and ordered mesopores to promote adsorption and desorption mass transfer, but remain satisfactory adsorption capacity of PAHs at low concentrations regarding the coexisting micropores. This paper focuses on introductions, comparisons and evaluations of various PAHs adsorbents and related characteristics, and proposes a prospect for the development of PAHs adsorption purification technology.

\section{BASIC PHYSICAL PROPERTIES AND CHEMICAL STRUCTURE OF PAHS}

PAHs are hydrocarbons - organic compounds containing only carbon and hydrogen, that are composed of multiple aromatic rings. Most of them have relatively high molecular symmetries. The Chemical structures of the 16 United States Environmental Protection Agency (U.S. EPA) priority PAH compounds is shown in Fig. 1 (Okparanma and Mouazen, 2013). The characteristic of 16 U.S. EPA priority PAHs are summarized in Table 1. They have molecular mass ranging from $128 \mathrm{~g} \mathrm{~mol}^{-1}$ for naphthalene to $278 \mathrm{~g} \mathrm{~mol}^{-1}$ for dibenzo[a,h]anthracene. Their boiling point increase with the increasing of the formula weight and ranging from $218^{\circ} \mathrm{C}$ for naphthalene to $542^{\circ} \mathrm{C}$ for benzo[g,h,i]perylene. The solubility, sorption, and vapour pressure for each PAH are important factors that determine the proportion in the environment (Huang et al., 2003). Low molecular weight or 2-3 rings PAHs usually found in gas-phase PAH concentrations, whilst those with four or more rings are found most in particle phase (Liu et al., 2017). PAHs are also known to exhibit very low water solubilities and hydrophobicities.

PAHs have been linked to skin, lung, bladder, liver, and stomach cancers in well-established animal model studies. As they have different chemical structure, the PAHs show a different toxicity and damage to human body. They can damage human body through inhalation, skin and eyes contact, drink and eating. The carcinogenicity of PAHs increases with increasing the increasing of formula weight. Their toxicity and preventive measures are also list simply in Table 1.

\section{ADSORPTION CHARACTERISTIC OF PAHS}

\section{Adsorption Equilibrium of PAHs}

The study on adsorption equilibrium of PAHs mainly involves the adsorption isotherm model and the equilibrium adsorption capacity.

\section{Adsorption on Active Carbon}

Because of high specific surface area (ranging from $300 \mathrm{~m}^{2} \mathrm{~g}^{-1}$ to $3000 \mathrm{~m}^{2} \mathrm{~g}^{-1}$ ) (Lamichhane, 2016) and low price, activated carbon is being a very popular in removal of pollution component, such as mercury (Tsai et al., 2017), formaldehyde (Shiue et al., 2018), $\mathrm{SO}_{2}$ (Liu et al., 2019), and also PAHs (Lamichhane, 2016).

Mastral et al. (2001a) obtained adsorption equilibrium parameters of PAHs on 16 different activated carbons, including asphalt-based, coal-based, apricot-based, cherrybased, grape-based, and coconut-shell activated carbons. On the basis of quasi-equilibrium adsorption tests for three PAHs (2-4 rings), naphthalene, phenanthrene, and pyrene, the narrow micropores (pore size $<0.7 \mathrm{~nm}$ ) were found to be more favorable for naphthalene adsorption, while the adsorption of phenanthrene is more dependent on the total pore volume and micropore distribution, and the adsorption of pyrene is directly related to the total volume of mesopores $(2-50 \mathrm{~nm})$. The difference in the pore size distributions between above carbon materials has a greater impact on PAHs adsorption as compared to the difference in surface functional groups. It is therefore judged that the textural characteristics of the adsorbent are dominant factors in PAHs adsorption. Ravenni et al. (2018) 
<smiles>c1ccc2ccccc2c1</smiles>

NAP<smiles>c1ccc2c(c1)ccc1ccccc12</smiles>

PHE<smiles>C1=Cc2cccc3cccc1c23</smiles>

ACY<smiles>c1ccc2c(c1)Cc1ccccc1-2</smiles>

FLU<smiles>c1cc2c3c(cccc3c1)CC2</smiles>

ACE<smiles></smiles>

PYR<smiles>c1ccc2cc3ccccc3cc2c1</smiles>

ANT<smiles></smiles>

FLT<smiles>c1ccc2c(c1)ccc1c3ccccc3ccc21</smiles>

CHR<smiles>c1ccc2c(c1)ccc1cc3ccc4ccccc4c3cc12</smiles>

DahA<smiles></smiles>

BghiP<smiles>c1ccc2cc3c(ccc4ccccc43)cc2c1</smiles>

BaA<smiles>c1ccc2cc3c(cc2c1)-c1cccc2cccc-3c12</smiles>

BkF<smiles>c1ccc2c(c1)cc1ccc3c2c2ccc4c5cccc1c5c4c32</smiles>

BaP<smiles>c1ccc2c(c1)-c1cccc3c1c-2cc1ccccc13</smiles>

BbF<smiles></smiles>

IcdP

Fig. 1. Chemical structures of the 16 U.S. EPA priority PAH compounds.

summarized the adsorption capacity of ACs on PAHs was mostly dependent on their porous-textural characteristics, especially microporosity.

In terms of the adsorbate, the work done by Mastral et al. (2003) extended to 7 PAHs and their adsorption isotherms on a certain coke at concentrations ranging from 0.020 to $25 \mathrm{ppm}$ and the temperature of $150^{\circ} \mathrm{C}$. The Langmuir and Freundlich models were found to describe the adsorption equilibrium of these PAHs well, the former one being suitable for naphthalene corresponding to either uniform and monolayer adsorption or microporous filling effect, and the latter one being suitable for phenanthrene, acenaphthene, and anthracene, etc. corresponding to non-uniform adsorption and multilayer adsorption. Ma et al. (2004) compared the PAHs adsorption on 6 adsorbents at conditions of flue gases, and obtained similar conclusions from Mastral et al. (2003), that is, the positive correlation of adsorption effect with the adsorbent's specific surface area and micropore volume. Zhou et al. (2010a) investigated the adsorption equilibrium of naphthalene on three activated carbons and pointed out the significant difference between granular and powder activated carbons exhibiting monolayer adsorption described by the Langmuir model and multilayer adsorption described by the BET model, respectively. Di Gregorio et al. (2016) investigated the removeal of naphthalene (reference tar compound) by active carbons at (750$900^{\circ} \mathrm{C}$ ), the results shows active carbon could reach a removal efficiencies of above $90 \%$, and adsorption contributed more than $90 \%$ of the removal efficiency.

Table 2 lists the equilibrium adsorption capacity of each adsorbate-adsorbent pair mentioned above. It's worth noting that the adsorption temperature of gaseous PAHs in the reference is generally set at $125-160^{\circ} \mathrm{C}$. This is because the study of gaseous PAHs adsorption is mainly directed to flue gas. For brief presentations and convenient comparisons, the similar equilibrium concentrations and the adsorbents giving higher adsorption capacities from different literatures are selected. It can be observed that for different PAHs, the variation rules of the adsorption capacity on different adsorbents are similar. The apricot-based and coal-based activated carbons with wider pore size distributions and larger average micropore diameters have higher PAHs adsorption capacities (Mastral et al., 2002a) probably attributed to the greater adsorption diffusion characteristics for macromolecular PAHs, which further demonstrates that physical textural properties play vital 
Table 1. Characteristic of 16 U.S. EPA priority PAHs.

\begin{tabular}{|c|c|c|c|c|c|c|}
\hline Name of PAH & Abbr. & $\begin{array}{l}\text { Molecular } \\
\text { formula }\end{array}$ & F. W. & $\begin{array}{l}\text { Boiling } \\
\text { point }\left({ }^{\circ} \mathrm{C}\right)\end{array}$ & $\mathrm{TEF}^{\mathrm{a}, \mathrm{b}}$ & Toxicity and preventive measures \\
\hline naphthalene & NAP & $\mathrm{C}_{10} \mathrm{H}_{8}$ & 128 & 218 & 0.001 & $\begin{array}{l}\text { Low toxicity, irritating skin, mucous } \\
\text { membranes, high concentration of } \\
\text { inhalation can lead to anemia, liver and } \\
\text { kidney damage, optic neuritis crystal } \\
\text { opacity }\end{array}$ \\
\hline acenaphthylene & $\mathrm{ACY}$ & $\mathrm{C}_{12} \mathrm{H}_{8}$ & 152 & 270 & 0.001 & Avoid inhalation, skin contact with eyes \\
\hline acenaphthene & $\mathrm{ACE}$ & $\mathrm{C}_{12} \mathrm{H}_{10}$ & 154 & 279 & 0.001 & $\begin{array}{l}\text { Micro-toxic, avoid inhalation, avoid } \\
\text { contact with eyes and skin }\end{array}$ \\
\hline fluorene & FLU & $\mathrm{C}_{13} \mathrm{H}_{10}$ & 166 & 294 & 0.001 & $\begin{array}{l}\text { avoid inhalation, avoid contact with eyes } \\
\text { and skin }\end{array}$ \\
\hline phenanthrene & PHE & $\mathrm{C}_{14} \mathrm{H}_{10}$ & 178 & 340 & 0.001 & $\begin{array}{l}\text { Irritating to the skin and carcinogenic } \\
\text { effects }\end{array}$ \\
\hline anthracene & ANT & $\mathrm{C}_{14} \mathrm{H}_{10}$ & 178 & 340 & 0.01 & $\begin{array}{l}\text { Mildly toxic, with mild local irritations } \\
\text { and weak light perception }\end{array}$ \\
\hline fluoranthene & FLT & $\mathrm{C}_{16} \mathrm{H}_{10}$ & 202 & 383 & 0.001 & $\begin{array}{l}\text { Micro-toxic, carcinogenic, corrosive, } \\
\text { avoid inhalation and skin contact }\end{array}$ \\
\hline pyrene & PYR & $\mathrm{C}_{16} \mathrm{H}_{10}$ & 202 & 404 & 0.001 & $\begin{array}{l}\text { Low toxicity, long-term exposure causes } \\
\text { blood cell changes }\end{array}$ \\
\hline 1,2-benzanthracene & $\mathrm{BaA}$ & $\mathrm{C}_{18} \mathrm{H}_{12}$ & 228 & 435 & 0.1 & $\begin{array}{l}\text { Carcinogenic, inhaled skin contact is } \\
\text { toxic, irreversible damage to the body }\end{array}$ \\
\hline Chrysene & CHR & $\mathrm{C}_{18} \mathrm{H}_{12}$ & 228 & 448 & 0.01 & $\begin{array}{l}\text { Carcinogenic, inhaled or skin contact is } \\
\text { toxic, irreversible damage to the body }\end{array}$ \\
\hline benzo[b]fluoranthene & $\mathrm{BbF}$ & $\mathrm{C}_{20} \mathrm{H}_{12}$ & 252 & 481 & 0.1 & Very carcinogenic \\
\hline benzo[k]fluoranthene & $\mathrm{BkF}$ & $\mathrm{C}_{20} \mathrm{H}_{12}$ & 252 & 481 & 0.1 & Very carcinogenic \\
\hline benzo[a]pyrene & $\mathrm{BaP}$ & $\mathrm{C}_{20} \mathrm{H}_{12}$ & 252 & 496 & 1 & $\begin{array}{l}\text { The most toxic carcinogen in polycyclic } \\
\text { aromatic hydrocarbons }\end{array}$ \\
\hline indeno[1,2,3-c,d]pyrene & IcdP & $\mathrm{C}_{22} \mathrm{H}_{12}$ & 276 & 534 & 0.1 & Less carcinogenic \\
\hline dibenzo[a,h]anthracene & DahA & $\mathrm{C}_{22} \mathrm{H}_{14}$ & 278 & 535 & 1 & $\begin{array}{l}\text { Carcinogenic, avoid inhalation or contact } \\
\text { with skin }\end{array}$ \\
\hline benzo[g,h,i]perylene & BghiP & $\mathrm{C}_{22} \mathrm{H}_{12}$ & 276 & 542 & 0.01 & $\begin{array}{l}\text { Inhalation or skin contact is toxic, } \\
\text { irreversible damage to the body }\end{array}$ \\
\hline
\end{tabular}

F.W. = Formula weight; ${ }^{\mathrm{a}}$ Liu et al., 2017; ${ }^{\mathrm{b}}$ Jin et al., 2018.

Table 2. Equilibrium adsorption capacities of PAH adsorbates on different adsorbents.

\begin{tabular}{|c|c|c|c|c|c|}
\hline Adsorbates & $\begin{array}{l}\text { Concentrations } \\
\left(\mathrm{mol} \mathrm{m}^{-3}\right)\end{array}$ & $\begin{array}{l}\text { Temperatures } \\
\left({ }^{\circ} \mathrm{C}\right)\end{array}$ & Adsorbents & $\begin{array}{l}\text { Equilibrium } \\
\text { adsorption } \\
\text { capacities } \\
\left(\mathrm{mmol} \mathrm{g}^{-1}\right)\end{array}$ & References \\
\hline naphthalene & 0.008 & 150 & CA-3 (coke) & 0.30 & Mastral et al., 2001a \\
\hline phenanthrene & 0.012 & & & 0.52 & \\
\hline pyrene & 0.007 & & & 0.53 & \\
\hline acenaphthene & 0.013 & 150 & RWE-1 (coke) & 0.26 & Mastral et al., 2003 \\
\hline fluorene & 0.012 & & & 0.43 & \\
\hline anthracene & 0.011 & & & 0.69 & \\
\hline phenanthrene & 0.011 & & & 0.67 & \\
\hline naphthalene & 0.016 & & & 1.00 & \\
\hline fluoranthene & 0.010 & & & 0.64 & \\
\hline pyrene & 0.010 & & & 0.69 & \\
\hline naphthalene & 0.014 & 160 & $\mathrm{AC}-1$ & 2.81 & Ma et al., 2004 \\
\hline fluorene & 0.018 & & & 1.81 & \\
\hline phenanthrene & 0.013 & & & 1.83 & \\
\hline \multirow[t]{3}{*}{ naphthalene } & 0.005 & 140 & $\mathrm{AC}-\mathrm{a}$ & 1.25 & Zhou et al., 2010a \\
\hline & & & $A C-b$ & 0.98 & \\
\hline & & & $\mathrm{AC}-\mathrm{c}$ & 1.72 & \\
\hline
\end{tabular}


Table 2. (continued).

\begin{tabular}{|c|c|c|c|c|c|}
\hline Adsorbates & $\begin{array}{l}\text { Concentrations } \\
\left(\mathrm{mol} \mathrm{m}^{-3}\right)\end{array}$ & $\begin{array}{l}\text { Temperatures } \\
\left({ }^{\circ} \mathrm{C}\right)\end{array}$ & Adsorbents & $\begin{array}{l}\text { Equilibrium } \\
\text { adsorption } \\
\text { capacities } \\
\left(\mathrm{mmol} \mathrm{g}^{-1}\right)\end{array}$ & References \\
\hline \multirow[t]{6}{*}{ acenaphthene } & 0.014 & 150 & CA-4 (tire) & 0.29 & Mastral et al., 2002a \\
\hline & & & CA-15 (coal) & 1.77 & \\
\hline & & & CA-16 (Apricot) & 2.05 & \\
\hline & & & CA-5 (cherry) & 0.03 & \\
\hline & & & CA-6 (grape) & 0.34 & \\
\hline & & & CA-11 (coconut) & 1.77 & \\
\hline \multirow[t]{6}{*}{ fluorene } & 0.012 & 150 & $\mathrm{CA}-4$ & 0.31 & \\
\hline & & & CA-12 (coal) & 2.05 & \\
\hline & & & CA-16 & 2.29 & \\
\hline & & & CA-5 & 0.02 & \\
\hline & & & CA-6 & 0.60 & \\
\hline & & & CA-11 & 1.93 & \\
\hline \multirow[t]{6}{*}{ phenanthrene } & 0.010 & 150 & CA-4 & 0.65 & \\
\hline & & & CA-15 & 2.73 & \\
\hline & & & CA-16 & 3.34 & \\
\hline & & & CA-5 & 0.12 & \\
\hline & & & CA-6 & 0.75 & \\
\hline & & & CA-11 & 2.73 & \\
\hline \multirow[t]{6}{*}{ anthracene } & 0.011 & 150 & CA-4 & 0.92 & \\
\hline & & & CA-13 & 2.83 & \\
\hline & & & CA-16 & 3.54 & \\
\hline & & & CA-5 & 0.10 & \\
\hline & & & CA-6 & 0.83 & \\
\hline & & & CA-11 & 3.03 & \\
\hline \multirow[t]{4}{*}{ naphthalene } & 0.006 & 120 & OMC-B90 & 0.51 & Wang et al., 2012 \\
\hline & & & OMC-B50 & 1.21 & \\
\hline & & & OMC-B0 & 1.48 & \\
\hline & & & OMC-B10 & 1.76 & \\
\hline \multirow[t]{7}{*}{ phenanthrene } & 0.007 & 150 & WSC & 2.13 & Garcia et al., 2004 \\
\hline & & & WCSN2 & 1.89 & \\
\hline & & & WSCN10 & 1.83 & \\
\hline & & & WSCN30 & 1.75 & \\
\hline & & & WSCN60 & 1.75 & \\
\hline & & & WSCO15 & 2.01 & \\
\hline & & & WSCO30 & 2.10 & \\
\hline naphthalene & 0.005 & 140 & AC- $\mathrm{C}_{\max }$ & 1.72 & Cai, 2011 \\
\hline acenaphthene & 0.002 & & $\mathrm{AC}-\mathrm{B}_{\max }$ & 1.82 & \\
\hline phenanthrene & 0.002 & & $\mathrm{AC}-\mathrm{B}_{\max }$ & 1.85 & \\
\hline naphthalene & 0.004 & 140 & $\mathrm{AC}-2_{\max }$ & 1.45 & Xue, 2011 \\
\hline acenaphthene & 0.003 & & $\mathrm{AC}-1_{\max }$ & 1.58 & \\
\hline phenanthrene & 0.003 & & $\mathrm{AC}-1_{\max }$ & 1.40 & \\
\hline \multirow[t]{3}{*}{ phenanthrene } & 0.002 & 125 & MCM-41 & 0.15 & Li et al., 2017a \\
\hline & & & SBA-15 & 0.32 & \\
\hline & & & CMK-3 & 2.82 & \\
\hline \multirow[t]{3}{*}{ naphthalene } & 0.005 & 125 & MCM-41 & 0.08 & Yang et al., 2015 \\
\hline & & & SBA-15 & 0.20 & \\
\hline & & & CMK-3 & 0.88 & \\
\hline \multirow[t]{3}{*}{ pyrene } & 0.0005 & 125 & MCM-41 & 0.18 & Li et al., 2017b \\
\hline & & & SBA-15 & 0.74 & \\
\hline & & & CMK-3 & 2.35 & \\
\hline \multirow[t]{2}{*}{ naphthalene } & 0.0005 & 125 & CMK-5 & 1.22 & Meng et al., 2017 \\
\hline & 0.0005 & & FDU-15 & 0.97 & \\
\hline
\end{tabular}


roles. For the same adsorbent, the PAHs adsorption capacity increases with increasing molecular weight or ring number, indicative of the increasing adsorption strength with the decrease in volatility.

\section{Adsorption on Mesoporous Materials}

Typical mesoporous adsorbents have showed a high adsorption capacity on VOCs adsorption for their tailorable pore system (Zeng and Bai, 2016). They have been commonly used for studying PAHs adsorption include ordered mesoporous silica MCM-41and SBA-15, and ordered mesoporous carbon CMK-3, CMK-5 (reversed structure of SBA-15 as the hard template in synthesis) and FDU-15 (micro-mesopore coexisting structure). Fig. 2 shows the structure diagrams of MCM-41, SBA-15 and CMK-3. MCM-41 is featured with unconnected and regular mesopores as one-dimensional (1D) channels (Beck et al., 1992), while SBA-15 has complementary micropores and small mesopores in the silica walls connecting the primary 1D mesopore channels forming a 2D hexagonal array (Zhao et al., 1998; Kosuge et al., 2007). As a negative replica structure of SBA-15 (Vinu et al., 2006), CMK-3 can be described as a network of carbon rods with ordered mesopores in between and micropores in the walls of the nanorods (Ryoo et al., 1999).

Wang et al. $(2012,2013)$ synthesized ordered mesoporous carbons (OMCs) with the soft template method and studied the naphthalene adsorption on them. The results showed that the Langmuir model fitted the naphthalene adsorption equilibrium on $\mathrm{OMC}$ with the pore size ranging from 2 to $3.5 \mathrm{~nm}$, showing a large adsorption affinity for naphthalene with the adsorption capacity as high as $1.76 \mathrm{~mol} \mathrm{~kg}^{-1}$ at the temperature of $120^{\circ} \mathrm{C}$ and the equilibrium concentration of $0.006 \mathrm{~mol} \mathrm{~m}^{-3}$. The works of Yang et al. (2015), Liu et al. (2016) and Li et al. (2017b), and studied the adsorption equilibrium of naphthalene, phenanthrene and pyrene on MCM-41, SBA-15 and CMK-3, respectively, demonstrating that sufficient micropores are the key factors in PAHs adsorption enhancement, and the importance of the mesoporous pore volume and pore size distribution grows with increasing PAH molecular weight. Naphthalene was subject to monolayer adsorption with distinct micropore filling pattern on CMK-3, while phenanthrene and pyrene with less micropore filling effect showed non-uniform adsorption states contributed by affinities from both micropores and mesopores. The Langmuir and Freundlich models are suitable for describing the adsorption equilibrium of PAHs with lower (naphthalene) and higher (pyrene) molecular weights, respectively. For phenanthrene with intermediate molecular weight, the Freundlich model performs better on SBA-15 while the Langmuir model performs better on MCM-41 and CMK-3. Meng et al. (2017) compared the adsorption equilibrium of naphthalene on CMK-3, CMK-5 and FDU-15, showing the good isotherm correlations with Langmuir and Sips models and the naphthalene adsorption capacity order of CMK-5 > CMK-3 > FDU-15. CMK-3, CMK-5 and FDU-15 are suitable for naphthalene adsorption at high concentrations, medium and low concentrations, and low concentrations, respectively.

For predicting the phase equilibrium of adsorption, Grand Canonical Monte Carlo method simulation is become a common techniques (Fan et al., 2017; Wang et al., 2018; Yang et al., 2019). Wang et al. (2018) use Grand Canonical Monte method to simulate the naphthalene adsorption behavior in $\mathrm{OMC}$, the results showed the adsorption isotherm curve is of the Langmuir IV type, the maximum capacity reached $105.4 \mathrm{mg} \mathrm{g}^{-1}$. Yang et al. (2019) use Grand Canonical Monte method to simulate naphthalene, phenanthrene, and pyrene adsorption behavior on MCM41 , the results showed the adsorption isotherm curve is belonged to Type I according to the IUPIC classification. And the adsorption capacity follows Pyr $>$ Phe $>$ Nap, the area of the $\pi$-electron plane on the PAHs increases with the increasing ring number lead to stronger adsorption interactions.

The adsorption equilibrium data for PAHs on mesoporous adsorbents in literatures are also summarized in Table 2. It can be seen that MCM-41 containing only mesopores has lower adsorption capacities of PAHs. The mesoporous materials with micro-mesoporous coexisting structures have higher PAHs adsorption capacities at lower
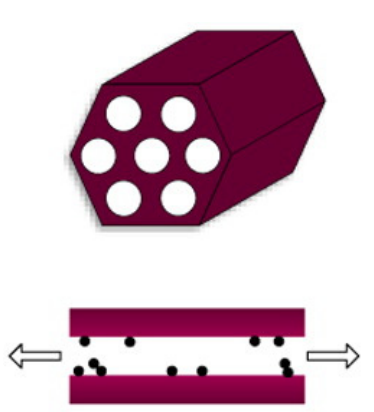

1-D mesopore channels
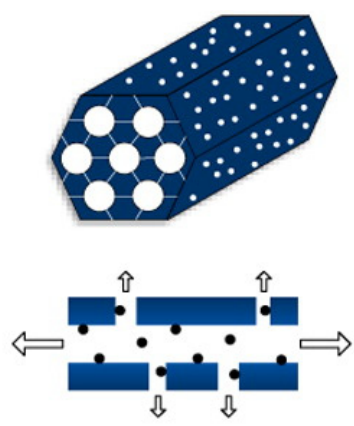

Micropores/small mesopores as interconnections
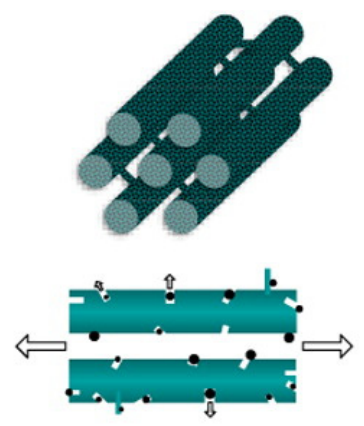

Network of carbon rods with micropores on walls

MCM-41

SBA-15

CMK-3

Fig. 2. Structure diagrams of MCM-41, SBA-15 and CMK-3 for PAHs adsorption. 
equilibrium concentrations, even higher than some conventional activated carbons, indicating the significant role of microporosity regarding PAHs adsorption at low concentrations. When the ring number of PAHs increases, the effects of mesopores become more significant and therefore mesoporous materials give higher adsorption capacities for high-ring PAHs.

\section{Adsorption Kinetics of PAHs}

The adsorption kinetics is another significant property for PAHs adsorbent in terms of the rates of adsorption and desorption, of which the studies mainly deal with the kinetic model fitting to experimental data of adsorption breakthrough curves. Afterwards, the internal, external and overall adsorption mass transfer coefficients can be obtained. Take the linear driving force (LDF) model as an example to introduce the three mass transfer coefficients (Li and Yang, 1999; Todd and Webley, 2002; Li et al., 2018), which follows the expressions as:

$$
\frac{\partial q}{\partial t}=k_{p}\left(q_{s}-q\right)
$$

where The term $\partial \mathrm{q} / \partial \mathrm{t}$ represents the local adsorption rate, $k_{p}$ is the internal mass-transfer coefficient in the stationary phase $\left(\mathrm{s}^{-1}\right) ; \mathrm{q}_{\mathrm{s}}$ is the concentration adsorbed at adsorbent surface $\left(\mathrm{mol} \mathrm{kg}^{-1}\right)$;

There are two other common expressions for the local adsorption rate in terms of the external and internal masstransfer coefficients as:

$$
\begin{gathered}
\rho \frac{\partial \bar{q}}{\partial t}=k_{f} \alpha\left(C-C_{s}\right) \\
\rho \frac{\partial \bar{q}}{\partial t}=k_{L} \alpha\left(C-C^{*}\right)
\end{gathered}
$$

where $\alpha$ is the mass-transfer area per unit volume of the bed; $\mathrm{C}$ is the gas concentration at the main liquid $\left(\mathrm{mol} \mathrm{m}^{-3}\right)$; $\mathrm{C}_{\mathrm{s}}$ is the gas concentration at the adsorbent exterior surface $\left(\mathrm{mol} \mathrm{m}^{-3}\right) ; \mathrm{k}_{\mathrm{f}}$ is the external mass-transfer coefficient across the gas film on the exterior surface of adsorbents $\left(\mathrm{m} \mathrm{s}^{-1}\right)$; $\mathrm{K}_{\mathrm{L}}$ is the overall liquid-phase mass-transfer coefficient $\left(\mathrm{m} \mathrm{s}^{-1}\right)$, and $\mathrm{K}_{\mathrm{L}} \alpha$ is called the volumetric mass-transfer coefficients $\left(\mathrm{s}^{-1}\right) ; \mathrm{C}^{*}$ is the gas phase concentration in equilibrium with the solid phase concentration $\mathrm{q}^{*}\left(\mathrm{~mol} \mathrm{~m}^{-3}\right)$, in the adsorption isotherm relationship expressed by $\mathrm{q}^{*}=$ $\mathrm{f}\left(\mathrm{C}^{*}\right)$. The relationship between the overall mass-transfer coefficient and the individual mass-transfer coefficients could be given by:

$\frac{1}{k_{L} \alpha}=\frac{1}{k_{f} \alpha}+\frac{C_{0}}{k_{p} \rho q_{0}}$

For the studies on conventional adsorbents, Murillo et al. (2004) used the simplified LDF mass transfer model to obtain the adsorption kinetics, providing $\mathrm{k}_{\mathrm{p}}$ of phenanthrene on three activated carbon materials ranging from $1 \times 10^{-3}$ to $2 \times 10^{-3} \mathrm{~s}^{-1}$ at an equilibrium concentration of $0.001 \mathrm{~mol} \mathrm{~m}^{-3}$. Mei et al. (2014) studied the adsorption kinetics of naphthalene on activated carbons at different temperatures and flow rates with a fixed-bed test and numerical prediction by the Yoon-Nelson mass transfer zone model giving the length and the moving of the mass transfer zone throughout the bed.

For adsorption kinetics of macromolecular PAHs on ordered mesoporous adsorbents, the advantages that are shown below have attracted attention. Yang et al. (2015) found that SBA-15 had higher adsorption rate for naphthalene due to the presence of micro-meso cross-linked pore structure, compared to MCM-41 with a 1-D mesopore structure. Liu et al. (2016) established an adsorption breakthrough curve model based on the constant concentration wave hypothesis, and explored the adsorption kinetics of naphthalene on three mesoporous adsorbents. The results indicated that internal diffusion was the main rate-control step for the adsorption and mass transfer of PAHs on mesoporous materials. The mesoporous structure can effectively reduce the internal diffusion resistance and improve the overall mass transfer coefficient. Li et al. (2017a) studied the adsorption and kinetics of phenanthrene on mesoporous silicas and carbon, showing that the large primary mesopore size and the cross-linked pore structure rich in micropores and fine mesopores contribute a lot to phenanthrene adsorption mass transfer. Based on three mesoporous carbon materials, Meng et al. (2017) further proved the important role of the micro-meso cross-linked pore structure in improving PAHs adsorption mass transfer, where the advantage of CMK-5 stands out.

Table 3 summarizes the adsorption kinetic parameters of naphthalene, phenanthrene and pyrene in three typical mesoporous adsorbents from literatures. As can be seen from the table, when the concentration is low and the PAHs molecular weight is small, the overall adsorption mass transfer rate follows CMK-3 > SBA-15 > MCM-41. When the concentration is higher and the molecular weight of the adsorbate is larger, the overall adsorption mass transfer rate follows SBA-15 > CMK-3 > MCM-41. Compared to traditional activated carbons, $\mathrm{k}_{\mathrm{p}}$ on the mesoporous material is higher at similar equilibrium concentrations indicating the small internal diffusion resistance and the greater mass transfer advantage which increases with increasing PAHs' molecules size. For the adsorption of small molecular naphthalene, the microporous filling on CMK-3 and the hydrophobicity of the carbon-based surface are obvious. For the adsorption of larger molecules of phenanthrene and pyrene, the role of mesopores on mass transfer is gradually enhanced. The larger mesopores and micro-meso crosslinked structures of SBA-15 exhibit significant diffusion advantages. CMK-3 exhibits higher mass transfer coefficients due to its larger mesopore volume. The one-dimensional smaller mesopores on MCM-41 gives simple adsorption diffusion behavior of PAHs and irregular variation of the diffusion coefficient with increasing concentration when the adsorbate's molecular size increases. 
Table 3. Adsorption kinetics parameters of PAHs on mesoporous adsorbents.

\begin{tabular}{|c|c|c|c|c|c|c|}
\hline Adsorbents & PAHs & $\begin{array}{l}C_{0} \\
\left(\mathrm{mmol} \mathrm{m}^{-3}\right)\end{array}$ & $\frac{k_{L} \alpha}{\left(\mathrm{s}^{-1}\right)}$ & $\frac{k_{\mathrm{f}} \alpha}{\left(\mathrm{s}^{-1}\right)}$ & $k_{P}$ & References \\
\hline ICB5 & \multirow[t]{13}{*}{ phenanthrene } & $1.79 \times 10^{-5}$ & - & - & $1.0 \times 10^{-3}$ & \multirow[t]{13}{*}{ Murillo et al., 2004} \\
\hline ICB5 & & $4.33 \times 10^{-5}$ & - & - & $1.5 \times 10^{-3}$ & \\
\hline ICB5 & & $1.12 \times 10^{-4}$ & - & - & $2.0 \times 10^{-3}$ & \\
\hline ICB5 & & $6.25 \times 10^{-4}$ & - & - & $2.5 \times 10^{-3}$ & \\
\hline ICB5 & & $2.68 \times 10^{-3}$ & - & - & $4.0 \times 10^{-3}$ & \\
\hline ICB8 & & $6.70 \times 10^{-5}$ & - & - & $1.0 \times 10^{-3}$ & \\
\hline ICB8 & & $3.13 \times 10^{-4}$ & - & - & $2.0 \times 10^{-3}$ & \\
\hline ICB8 & & $1.25 \times 10^{-3}$ & - & - & $3.0 \times 10^{-3}$ & \\
\hline ICB8 & & $3.30 \times 10^{-3}$ & - & - & $5.0 \times 10^{-3}$ & \\
\hline $\mathrm{ICB} 12$ & & $8.04 \times 10^{-5}$ & - & - & $1.0 \times 10^{-3}$ & \\
\hline ICB12 & & $2.86 \times 10^{-4}$ & - & - & $2.0 \times 10^{-3}$ & \\
\hline $\mathrm{ICB} 12$ & & $1.65 \times 10^{-3}$ & - & - & $3.5 \times 10^{-3}$ & \\
\hline ICB12 & & $3.79 \times 10^{-3}$ & - & - & $4.5 \times 10^{-3}$ & \\
\hline \multirow[t]{3}{*}{ SBA-15 } & \multirow[t]{3}{*}{ naphthalene } & 0.143 & 2.72 & $7.2 \times 10^{3}$ & $5.0 \times 10^{-3}$ & \multirow[t]{3}{*}{ Liu et al., 2016} \\
\hline & & 0.949 & 3.13 & $7.2 \times 10^{3}$ & $2.6 \times 10^{-3}$ & \\
\hline & & 2.76 & 9.71 & $7.2 \times 10^{3}$ & $8.9 \times 10^{-4}$ & \\
\hline \multirow[t]{3}{*}{ SBA-15 } & \multirow[t]{3}{*}{ phenanthrene } & 0.097 & 6.51 & $6.3 \times 10^{3}$ & $1.5 \times 10^{-3}$ & \multirow[t]{3}{*}{ Li et al., 2017a } \\
\hline & & 0.41 & 7.08 & $6.3 \times 10^{3}$ & $1.8 \times 10^{-3}$ & \\
\hline & & 2.2 & 15.51 & $6.3 \times 10^{3}$ & $3.7 \times 10^{-3}$ & \\
\hline \multirow[t]{3}{*}{ SBA-15 } & \multirow[t]{3}{*}{ pyrene } & 0.29 & 20.27 & $5.0 \times 10^{3}$ & $5.2 \times 10^{-4}$ & \multirow[t]{3}{*}{ Meng et al., 2017} \\
\hline & & 0.46 & 22.93 & $5.0 \times 10^{3}$ & $1.3 \times 10^{-3}$ & \\
\hline & & 0.71 & 53.49 & $5.0 \times 10^{3}$ & $2.9 \times 10^{-3}$ & \\
\hline \multirow[t]{3}{*}{ MCM-41 } & \multirow[t]{3}{*}{ naphthalene } & 0.143 & 1.61 & $4.9 \times 10^{3}$ & $3.5 \times 10^{-3}$ & \multirow[t]{3}{*}{ Liu et al., 2016} \\
\hline & & 0.949 & 2.52 & $4.9 \times 10^{3}$ & $17 \times 10^{-3}$ & \\
\hline & & 2.76 & 7.43 & $4.9 \times 10^{3}$ & $7.5 \times 10^{-3}$ & \\
\hline \multirow[t]{3}{*}{ MCM-41 } & \multirow[t]{3}{*}{ phenanthrene } & 0.097 & 6.02 & $6.5 \times 10^{3}$ & $2.9 \times 10^{-3}$ & \multirow[t]{3}{*}{ Li et al., 2017a } \\
\hline & & 0.41 & 7.53 & $6.5 \times 10^{3}$ & $3.6 \times 10^{-3}$ & \\
\hline & & 2.2 & 9.63 & $6.5 \times 10^{3}$ & $4.2 \times 10^{-3}$ & \\
\hline \multirow[t]{3}{*}{ MCM-41 } & \multirow[t]{3}{*}{ pyrene } & 0.29 & 23.47 & $5.4 \times 10^{3}$ & $1.5 \times 10^{-3}$ & \multirow[t]{3}{*}{ Meng et al., 2017} \\
\hline & & 0.46 & 9.98 & $5.4 \times 10^{3}$ & $9.8 \times 10^{-4}$ & \\
\hline & & 0.71 & 12.16 & $5.4 \times 10^{3}$ & $1.0 \times 10^{-3}$ & \\
\hline \multirow[t]{3}{*}{ CMK-3 } & \multirow[t]{3}{*}{ naphthalene } & 0.143 & 73.4 & $1.6 \times 10^{4}$ & $7.5 \times 10^{-3}$ & \multirow[t]{3}{*}{ Liu et al., 2016} \\
\hline & & 0.949 & 5.5 & $1.6 \times 10^{4}$ & $8.9 \times 10^{-4}$ & \\
\hline & & 2.76 & 30.6 & $1.6 \times 10^{4}$ & $7.9 \times 10^{-3}$ & \\
\hline \multirow[t]{3}{*}{ CMK-3 } & \multirow[t]{3}{*}{ phenanthrene } & 0.097 & 6.43 & $1.4 \times 10^{4}$ & $4.1 \times 10^{-4}$ & Li et al., 2017a \\
\hline & & 0.41 & 7.7 & $1.4 \times 10^{4}$ & $9.7 \times 10^{-4}$ & \\
\hline & & 2.2 & 9.87 & $1.4 \times 10^{4}$ & $1.1 \times 10^{-3}$ & \\
\hline CMK-3 & pyrene & 0.29 & 51.86 & $1.4 \times 10^{4}$ & $2.8 \times 10^{-3}$ & Meng et al., 2017 \\
\hline & & 0.46 & 36.71 & $1.4 \times 10^{4}$ & $2.2 \times 10^{-3}$ & \\
\hline & & 0.71 & 14.62 & $1.4 \times 10^{4}$ & $9.9 \times 10^{-4}$ & \\
\hline
\end{tabular}

\section{PAHs Adsorption Influential Factors}

Effect of Surface Functional Groups

The PAHs are uncharged and non-polar molecules molecule with planar ring structures. Many studies have shown that the difference in surface functional groups of the adsorbent has little effect on PAHs adsorption, especially for those with higher symmetries such as naphthalene and pyrene. Mastral et al. (2001b) showed that the main factor influencing PAHs adsorption is not the active site on the adsorbent, but the physical properties of the pore size distribution and the pore structure Mastral et al. (2002b). The result shows PAH adsorption capacities on carbons is positively correlated with pore volume. Some work showed that reducing the original oxygen-containing functional groups of activated carbons can effectively increase the adsorption capacity of phenanthrene, and the presence of oxygen surface groups (i.e., both $\mathrm{CO}$ and $\mathrm{CO}_{2}$-type groups) can lead to a decrease in phenanthrene adsorption capacity Mastral et al. (2004). This is because the adsorption of phenanthrene will involve the interaction of the electronrich regions located in graphene layers with the $\pi$ electrons of the aromatic compounds. The increasing of the oxygen groups on active carbon results in electron withdrawal from the graphene layers ( $\pi-\pi$ argument), and consequently decreases the specific interaction between phenanthrene and the carbon surface. Considering that the cyclic molecules of PAHs may exhibit the $\pi$-electron interaction with the surface graphene ring, it is believed that the adsorption of 
PAHs is mainly subject to physical adsorption with potentially weak chemical interactions. Mastral et al. (2004) claimed that for active carbons the critical preferential physical factors for PAHs adsorption include the appropriate pore size with diameter approximately twice the $\mathrm{PAH}$ molecular size besides the highly developed porosity.

\section{Effect of $\mathrm{CO}_{2}$}

$\mathrm{CO}_{2}$ is a common component in flue gases, which is easy to form competitive adsorption with trace amounts of PAHs on adsorbents. Mastral et al. (2002c) found there exists a negative influence of $\mathrm{CO}_{2}$ on phenanthrene adsorption as shown in Fig. 3. The figure gives different adsorption isotherms of phenanthrene on a carbonaceous material at different $\mathrm{CO}_{2}$ concentrations, and shows that $15 \%$ of $\mathrm{CO}_{2}$ decreases phenanthrene adsorption capacity by $24 \%$. However, the negative influence of $\mathrm{CO}_{2}$ fails to increase significantly with $\mathrm{CO}_{2}$ concentrations, as evidenced by the nearly unchanged phenanthrene adsorption capacity when $\mathrm{CO}_{2}$ concentration increases from $10 \%$ to $30 \%$. It can be judged that a robust PAHs adsorbent should possess a wide pore size distribution and a higher average micropore diameter which are helpful to inhibit strong competitive adsorption of $\mathrm{CO}_{2}$. From this perspective, the development of mesoporosity in adsorbents promotes phenanthrene adsorption because it is able to either favor the access of phenanthrene molecules into the micropores to form potentially multilayer adsorption or weaken $\mathrm{CO}_{2}$ competitive adsorption.

\section{Effect of Moisture}

Influences of moisture on phenanthrene adsorption on 16 carbonaceous materials was once studied by Mastral et al. (2002d). The influence was largely associated with the microporosity of the adsorbent. The effect of moisture on
Phe adsorption was positively correlated with the narrow micropore volume (pore size diameter $<0.7 \mathrm{~nm}$ ) with a statistical significance level higher than $99 \%$. This is probably due to the fact that at low humidity partial pressures, the water molecules are retained mainly in the molecular size micropores (ca. $0.3 \mathrm{~nm}$ ). Therefore, the higher the narrow microporosity is, the higher the water adsorption and the lower the Phe adsorption.

\section{DESORPTION PROPERTIES OF PAHS}

The desorption characteristics is highly related to the cyclic performance of the adsorbent as well as the energy consumption during actual operation which is a big challenge to practical applications, particularly for the low-volatility PAHs at low concentrations. The most widely used method for obtaining desorption information is based on thermogravimetric analysis (TGA), in which temperatureprogrammed desorption (TPD) is recorded under any heating profile (Park and Yang 2005; Adelodun et al., 2016). The key kinetic information (or, "kinetic triplet") - the activation energy, the pre-exponential factor, and the kinetic modelcan be determined with combined kinetic analysis of experimental data (Perez-Maqueda et al., 2002). According to this line of research, previous studies have dealt with the adsorbents for desorption of organic pollutants, such as dibenzo-p-furane on zeolites (Xi et al., 2003). The peak desorption and the desorption activation energy are two key parameters that have been studied in research of PAHs desorption properties.

Li et al. (2016) investigated desorption performances of naphthalene and pyrene on mesoporous MCM-41, SBA-15, and CMK-3 at the temperature of $350-800 \mathrm{~K}$ and different heating rates based on temperature-programmed desorption (TPD) experiments, and obtained the desorption activation

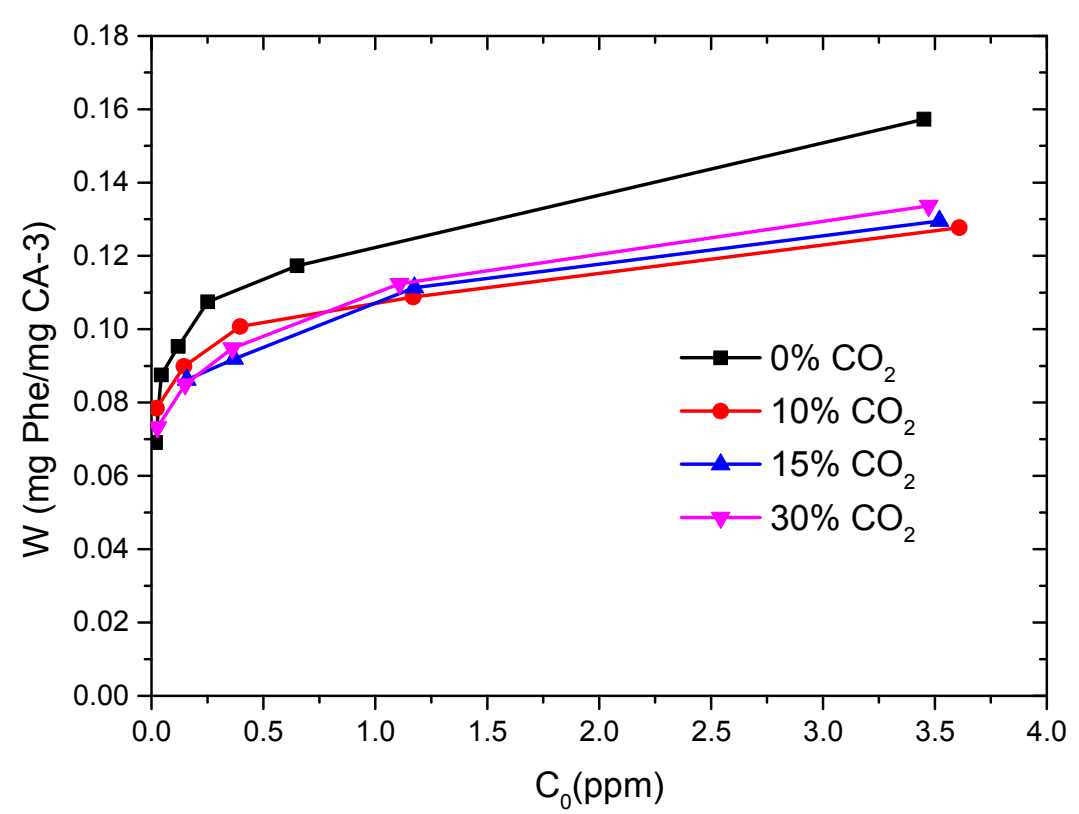

Fig. 3. Phenanthrene adsorption isotherms on a carbonaceous material (CA-3 sample) at different $\mathrm{CO}_{2}$ concentrations $\left(\mathrm{T}=150^{\circ} \mathrm{C}, 0.02<\mathrm{C}_{0}<3 \mathrm{ppmv}\right)$. 
energy, pre-exponential factor, and kinetic model for each adsorbate-adsorbent pair with a combined model-fitting method. The results showed SBA-15 with interconnectivity between adjacent mesopores offered diffusion advantages in desorption, which contributes to the order of the degree of ease in desorption: SBA-15 > MCM-41 > CMK-3. Subsequently, the desorption kinetics of naphthalene and anthracene on two activated carbons were also studied by a similar method (Li et al., 2015). The Johnson-MehlAvrami (JMA) rate equation following the nucleation and growth model was found to best describe the PAH desorption from both adsorbents, showing significant molecular sieving effects on desorption characteristics. The active carbons with less narrow micropore $(<0.7 \mathrm{~nm})$ volume and more wide micropores $(0.7-2 \mathrm{~nm}$ ) favor PAH adsorption and desorption rates. Zhou et al. (2010b) used the main curve method to study the desorption kinetics of naphthalene and acenaphthene on activated carbons, and pointed out that the mechanism of desorption rate is correlated with the JMA equation. The average desorption activation energies of naphthalene and acenaphthene calculated by the iso-conversional method are 65.89 and $96.13 \mathrm{~kJ} \mathrm{~mol}^{-1}$, respectively. Guilloteau et al. (2008, 2010) studied the desorption characteristics of 3-5 ring PAHs on laboratory-generated kerosene soot surfaces, and obtained the Arrhenius expression based on analysis of the desorption rate constant and desorption activation energy. $\mathrm{Su}$ et al. (2010) worked on the adsorption and desorption properties of C2-C12 VOCs on MCM-48, and found that the mesoporosity was able to effectively reduce the desorption temperature $\left(100-180^{\circ} \mathrm{C}\right)$ compared with conventional carbon materials. The facile desorption was accompanied by a low memory effect, since the large mesopores of
MCM-48 could be regenerated more efficiently during thermal desorption.

Table 4 summarizes the TPD peak temperatures and the desorption activation energies of PAHs on conventional activated carbons and mesoporous adsorbents. It can be clearly seen that the desorption temperatures of PAHs on mesoporous adsorbents are lower than those on activated carbons, indicating the promoted macromolecular diffusion and mass transfer characteristics by mesopores. For the desorption activation energy, SBA-15 and CMK-3 with co-existing micropores and mesopores also give lower values as compared to activated carbons, largely attributed to their special micro-meso cross-linked pore structures. However, MCM-41 with one-dimensional mesoporosity fails to show significant advantages of desorption over activated carbons. Table 4 also shows the TPD peak temperatures and desorption activation energies of PAHs on the same adsorbent increase with the increasing of the molecular weight. It is indicated the energy required for desorption of PAHs from adsorbent increases with the increase of molecules. This is because the PAHs with higher molecular weight have stronger adsorption interactions due to larger $\pi$-electron plane area on the PAHs. This is consistent with the adsorption capacity of PAHs on adsorbent.

\section{APPLICATION RESEARCHES OF PAHS ADSORPTION PURIFICATION}

Current researches on practical applications of PAHs adsorption primarily involve flue gas purification, cigarette filtration, and sampling and detection. With the increasing strict environmental protection standards in recent years, the application researches on PAHs adsorption purification

Table 4. Parameters of PAHs thermal desorption on various sorbents.

\begin{tabular}{|c|c|c|c|c|}
\hline Adsorbents & Adsorbate & $\begin{array}{l}\text { TPD peak temperature } \\
(\mathrm{K})\end{array}$ & $\begin{array}{l}\text { desorption activation } \\
\text { energy }\left(\mathrm{kJ} \mathrm{mol}^{-1}\right)\end{array}$ & References \\
\hline MCM-41 & phenanthrene & $452-472$ & 68.7 & Li et al., 2017a \\
\hline SBA-15 & & $452-464$ & 116.2 & \\
\hline CMK-3 & & $482-496$ & 127.0 & \\
\hline \multirow[t]{2}{*}{$\mathrm{AC}_{\mathrm{WY}}$} & naphthalene & $505-534$ & 65.14 & Li et al., 2015 \\
\hline & acenaphthene & $569-599$ & 83.81 & \\
\hline \multirow[t]{2}{*}{$\mathrm{AC}_{\mathrm{NT}}$} & naphthalene & $515-535$ & 101.40 & \\
\hline & acenaphthene & $613-636$ & 124.91 & \\
\hline MCM-41 & naphthalene & $384-400$ & 73.55 & Li et al., 2016 \\
\hline SBA-15 & & $369-387$ & 59.76 & \\
\hline CMK-3 & & $422-441$ & 77.92 & \\
\hline MCM-41 & pyrene & $494-509$ & 129.04 & \\
\hline SBA-15 & & $480-512$ & 54.87 & \\
\hline CMK-3 & & $514-538$ & 87.03 & \\
\hline CMK-5 & naphthalene & $395-409$ & 57.23 & Meng et al., 2017 \\
\hline FDU-15 & & $428-434$ & 47.09 & \\
\hline \multirow[t]{4}{*}{$\mathrm{AC}$} & naphthalene & $535-575$ & 65.89 & Xue, 2011 \\
\hline & acenaphthene & $617-637$ & 96.13 & \\
\hline & phenanthrene & $690-719$ & 105.62 & \\
\hline & fluoranthene & $743-779$ & 128.03 & \\
\hline \multirow[t]{2}{*}{$\mathrm{AC}$} & naphthalene & $535-575$ & 65.89 & Zhou et al., 2010b \\
\hline & acenaphthene & $617-638$ & 96.13 & \\
\hline
\end{tabular}


from flue gases has been increasing, where traditional activated carbons are widely accepted mainly due to the cheapness. Mesoporous adsorbents with relatively higher prices are mainly used in cigarette filtration and smallscale atmospheric sampling and detection.

For the PAHs purification in flue gases, Aranda et al. (2007) used the temperature swing adsorption technology with activated carbons to study the adsorptive removal of typical PAHs in the hot flue gas. The results showed that the adsorption performance largely depended on adsorbent characteristics such as total micropore volume and micropore size distribution. It was found that the adsorption capacity of naphthalene remained unchanged with adsorption cycling, while that of phenanthrene dropped sharply after the first run and is stabilized afterwards. Mastral et al. (2001c) added limestone mixed with pulverized coal in a circulating fluidized combustion bed for PAHs removal in flue gases, and found that it can reduce the emissions of gaseous PAHs as well as the conversion to particulate matters. Zhong et al. (2008) presented the research of PAHs adsorption purification in municipal solid wastes (MSW) incineration with in-pipe jet adsorption techniques, showed the increasing removal effectiveness with increasing injection weight of adsorbents, and gave the order of adsorbent performance in PAHs purification of kaolin $>$ activated carbon $>$ activated bauxite. Zhou et al. (2005) studied the effect of pipe-sprayed activated carbons on the removal of PAHs from the municipal solid waste flue gas, and showed appealing removal efficiencies of PAHs ranging from $76 \%$ to $91 \%$. With the increase of the adsorbent feeding rate, the concentrations of three- to six-ring PAHs in fly ash increased, and those of two-ring PAHs decreased.

For other application researches of PAHs, Meier and Siegmann (1999) added 4\% of $\mathrm{NaY}$ to the cigarette to reduce PAHs and nitrosamines, showed significant reductions of PAHs in the smoke with an efficiency of $43 \pm 9 \%$. Zhou et al. $(2004,2008)$ demonstrated that $\mathrm{Y}$ zeolite had a better PAHs adsorption performance compared to ZSM-5 in purifying the cigarette smoke. The NaY zeolite coated with $\mathrm{CuO}$ significantly enhanced the PAHs removal efficiency with the optimal condition of $3 \% \mathrm{CuO} / \mathrm{NaY}$. This novel material with nano-pore structures can effectively reduce $30 \%-60 \%$ of harmful contents like PAHs and nitrosamines in cigarette smoke. Yong et al. (2006) studied the adsorption characteristics of PAHs in cigarette smoke with MCM-48 and Ce-MCM-48, showing that the incorporation of cerium into MCM-48 as mesoporous shape-selective adsorption/catalysts can effectively improve the catalytic activity and PAH removal. Lee et al. (2006) investigated the adsorption properties of 7 semi-volatile PAHs (including acenaphthylene, acenaphthene, fluorene, phenanthrene, anthracene, fluoranthene and pyrene) on a studied the adsorption properties resin XAD-4. The results showed the 4-ring PAHs are more easily adsorbed than the 3-ring PAHs, because the area of the $\pi$-electron plane on the PAHs increases with the increasing ring number, lead to stronger adsorption interactions. The physical behavior of PAHs on XAD-4 might involve an aerosol form rather than a gaseous adsorption.

\section{CONCLUSIONS}

(1) The adsorption purification studies of gaseous PAHs focus on the selection of adsorbents and the adsorption and desorption characteristics. Conventional activated carbons have the advantages of low price and high adsorption capacity for PAHs at low concentrations and disadvantages of low adsorption uptake rate and high desorption energy consumption. Mesoporous adsorbents have satisfactory adsorption capacity, higher adsorption rate, more facile desorption and greater sustainability compared to activated carbons. This is because mesoporous adsorbents have high pore volume, larger pore size and micro-meso cross-linked pore structure, it will effectively reduce the internal diffusion resistance and improve the overall mass transfer coefficient on adsorption and desorption.

(2) The adsorption of PAHs is mainly physical adsorption, and a wide pore size distribution is the key factor for a robust PAHs adsorbent. Microporosity is to PAHs adsorption at low concentrations, but too many narrow micropores would lead to mass transfer diffusional troubles and higher desorption temperatures and activation energies. Mesoporosity can promote adsorption and desorption rate, lower the desorption temperature, reduce the negative effects of moisture, $\mathrm{CO}_{2}$ and other impurity gases on PAHs adsorption.

(3) For mesoporous adsorbents, the regulation of micromeso cross-linking structure is the key factor to obtain the optimal balance between adsorption and desorption of PAHs. Benefiting from this, SBA-15 and CMK-5 are found to be the preferred silica-based and carbon-based PAHs mesoporous adsorbents, respectively.

\section{ACKNOWLEDGMENTS}

This research was supported by the National Natural Science Foundation of China (51604016, 21676025, 51478083), National Key R\&D Program of China (No. 2017YFC0210302), the National Postdoctoral Program for Innovative Talents (No. BX201700029), Beijing Natural Science Foundation (No. 8174064, 8182019), the China Postdoctoral Science Foundation (No. 2018M630075) and the Fundamental Research Funds for the Central Universities (No. FRF-TP-17-063A1, FRF-BD-18-015A).

\section{REFERENCES}

Adelodun, A.A., Ngila, J.C., Kim, D.G. and Jo, Y.M. (2016). Isotherm, thermodynamic and kinetic studies of selective $\mathrm{CO}_{2}$ adsorption on chemically modified carbon surfaces. Aerosol Air Qual. Res. 16: 3312-3329.

Aranda, A., Navarro, M.V., García, T., Murillo, R. and Mastral, A.M. (2007). Temperature swing adsorption of polycyclic aromatic hydrocarbons on activated carbons. Ind. Eng. Chem. Res. 46: 8193-8198.

Beck, J.S., Vartuli, J.C., Roth, W.J., Leonowicz, M.E., Kresge, C.T., Schmitt, K.D., Chu, C.T.W., Olson, D.H., Sheppard, E.W., McCullen, S.B., Higgins, J.B. and Schlenker, J.L. (1992). A new family of mesoporous 
molecular sieves prepared with liquid crystal templates. J. Am. Chem. Soc. 114: 10834-10843.

Cai, H.X. (2011). Study on static and dynamic adsorption behaviors of PAHs in flue gas. Master's thesis, Nanjing University of Information Science \& Technology, Nanjing, China.

Cheng, X., Kan, A.T. and Tomson, M.B. (2004). Naphthalene adsorption and desorption from aqueous C60 fullerene. J. Chem. Eng. Data 49: 675-683.

Dat, N.D., Lyu, J.M. and Chang, M.B. (2018). Variation of atmospheric PAHs in northern Taiwan during winter and summer seasons. Aerosol Air Qual. Res. 18: 10191031.

Di Gregorio, F., Parrillo, F., Salzano, E., Cammarota, F. and Arena, U. (2016). Removal of naphthalene by activated carbons from hot gas. Chem. Eng. J. 291: 244253.

Fan, F., Zhang, M., Peng, Z., Chen, J., Su, M., Moghtaderi, B. and Doroodchi, E. (2017). Direct simulation Monte Carlo method for acoustic agglomeration under standing wave condition. Aerosol Air Qual. Res. 17: 1073-1083.

García, T., Murillo, R., Cazorla-Amorós, D., Mastral, A.M. and Linares-Solano, A. (2004). Role of the activated carbon surface chemistry in the adsorption of phenanthrene. Carbon 42: 1683-1689.

Ghafari, M. and Atkinson, J.D. (2018). Impact of styrenic polymer one-step hyper-cross-linking on volatile organic compound adsorption and desorption performance. $J$. Hazard. Mater. 351: 117-123.

Guilloteau, A., Nguyen, M.L., Bedjanian, Y. and Le Bras, G. (2008). Desorption of polycyclic aromatic hydrocarbons from soot surface: Pyrene and fluoranthene. J. Phys. Chem. A 112: 10552-10559.

Guilloteau, A., Bedjanian, Y., Nguyen, M.L. and Tomas, A. (2010). Desorption of polycyclic aromatic hydrocarbons from a soot surface: Three- to five-ring PAHs. J. Phys. Chem. A 114: 942-948.

Huang, W., Peng, P.a., Yu, Z. and Fu, J. (2003). Effects of organic matter heterogeneity on sorption and desorption of organic contaminants by soils and sediments. Appl. Geochem. 18: 955-972.

Jin, T., Han, M., Han, K., Fu, X., Xu, L. and Xu, X. (2018). Health risk of ambient $\mathrm{PM}_{10}$-bound PAHs at bus stops in spring and autumn in Tianjin, China. Aerosol Air Qual. Res. 18: 1828-1838.

Keith, L. and Telliard, W. (1979). ES\&T Special Report: Priority pollutants: I-a perspective view. Environ. Sci. Technol. 13: 416-423.

Kosuge, K., Kubo, S., Kikukawa, N. and Takemori, M. (2007). Effect of pore structure in mesoporous silicas on VOC dynamic adsorption/desorption performance. Langmuir 23: 3095-3102.

Lamichhane, S., Krishna, K.C.B. and Sarukkalige, R. (2016). Polycyclic aromatic hydrocarbons (PAHs) removal by sorption: A review. Chemosphere 148: 336-353.

Lee, J.J. and Chuang, C.J. (2006). The characteristics of nano-scale adsorption mechanism on the collection of semi-volatile PAHs with XAD-4 porous adsorbent. Chin. J. Process Eng. 6: 150-154.
Li, Z. and Yang, R.T. (1999). Concentration profile for linear driving force model for diffusion in a particle. AIChE J. 45: 196-200.

Li, Z., Liu, Y., Yang, X., Xing, Y., Wang, Z., Yang, Q. and Yang, R.T. (2015). Desorption kinetics of naphthalene and acenaphthene over two activated carbons via thermogravimetric analysis. Energy Fuels 29: 53035310.

Li, Z., Liu, Y., Yang, X., Xing, Y., Tsai, C., Wang, Z., Yang, Q. and Yang, R.T. (2016). Desorption of polycyclic aromatic hydrocarbons on mesoporous sorbents: Thermogravimetric experiments and kinetics study. Ind. Eng. Chem. Res. 55: 1183-1191.

Li, Z., Liu, Y., Yang, X., Xing, Y., Tsai, C.J., Meng, M. and Yang, R.T. (2017a). Performance of mesoporous silicas and carbon in adsorptive removal of phenanthrene as a typical gaseous polycyclic aromatic hydrocarbon. Microporous Mesoporous Mater. 239: 9-18.

Li, Z., Liu, Y., Yang, X., Xing, Y., Yang, Q. and Yang, R.T. (2017b). Adsorption thermodynamics and desorption properties of gaseous polycyclic aromatic hydrocarbons on mesoporous adsorbents. Adsorption 23: 361-371.

Li, Z., Liu, Y., Wang, H., Tsai, C.J., Yang, X., Xing, Y., Zhang, C., Xiao, P. and Webley, P.A. (2018). A numerical modelling study of $\mathrm{SO}_{2}$ adsorption on activated carbons with new rate equations. Chem. Eng. J. 353: 858-866.

Liu, J., Wang, Y., Li, P.H., Shou, Y.P., Li, T., Yang, M.M., Wang, L., Yue, J.J., Yi, X.L. and Guo, L.Q. (2017). Polycyclic aromatic hydrocarbons (PAHs) at high mountain site in North China: Concentration, source and health risk assessment. Aerosol Air Qual. Res. 17: 2867-2877.

Liu, S., Yu, X., Lin, G., Qu, R., Zheng, C. and Gao, X. (2019). Insights into the effect of adsorption-desorption cycles on $\mathrm{SO}_{2}$ removal over an activated carbon. Aerosol Air Qual. Res. 19: 411-421.

Liu, Y., Li, Z., Yang, X., Xing, Y., Tsai, C., Yang, Q., Wang, Z. and Yang, R.T. (2016). Performance of mesoporous silicas (MCM-41 and SBA-15) and carbon (CMK-3) in the removal of gas-phase naphthalene: Adsorption capacity, rate and regenerability. RSC $A d v$. 6: 21193-21203.

Liu, Z.S., Wey, M.Y. and Lin, C.L. (2002). Simultaneous control of acid gases and PAHs using a spray dryer combined with a fabric filter using different additives. $J$. Hazard. Mater. 91: 129-141.

Long, A.S., Lemieux, C.L., Gagné, R., Lambert, I.B. and White, P.A. (2017). Genetic toxicity of complex mixtures of polycyclic aromatic hydrocarbons: Evaluating doseadditivity in a transgenic mouse model. Environ. Sci. Technol. 51: 8138-8148.

Lovett, C., Shirmohammadi, F., Sowlat, M.H. and Sioutas, C. (2018). Commuting in Los Angeles: Cancer and noncancer health risks of roadway, light-rail and subway transit routes. Aerosol Air Qual. Res. 18: 2363-2374.

Ma, Z., Chen, H., Li, W. and Li, B. (2004). Polycyclic aromatic hydrocarbons removal from hot gas by porous sorbent adsorption. J. Fuel Chem. Technol. 32: 526-530. 
Mastral, A.M., GarcÍa, T., Callén, M.S., Navarro, M.V. and Galbán, J. (2001a). Removal of naphthalene, phenanthrene, and pyrene by sorbents from hot gas. Environ. Sci. Technol. 35: 2395-2400.

Mastral, A.M., García, T., Callén, M.S., Navarro, M.V. and Galbán, J. (2001b). Assessement of phenanthrene removal from hot gas by porous carbons. Energy Fuels 15: $1-7$.

Mastral, A.M., Garcia, T., Callén, M.S., Lopez, J.M., Murillo, R. and Navarro, M.V. (2001c). Effects of limestone on polycyclic aromatic hydrocarbon emissions during coal atmospheric fluidized bed combustion. Energy fuels 15: 1469-1474.

Mastral, A.M., García, T., Callén, M.S., López, J.M., Navarro, M.V., Murillo, R. and Galbán, J. (2002a). Three-ring PAH removal from waste hot gas by sorbents: Influence of the sorbent characteristics. Environ. Sci. Technol. 36: 1821-1826.

Mastral, A.M., García, T., Callén, M.S., Murillo, R., Navarro, M.V. and López, J.M. (2002b). Sorbent characteristics influence on the adsorption of PAC: I. PAH adsorption with the same number of rings. Fuel Process. Technol. 77: 373-379.

Mastral, A.M., Garcia, T., Murillo, R., Callen, M.S., Lopez, J.M. and Navarro, M.V. (2002c). Effects of $\mathrm{CO}_{2}$ on the phenanthrene adsorption capacity of carbonaceous materials. Energy Fuels 16: 510-516.

Mastral, A.M., Garcia, T., Murillo, R., Callen, M.S., Lopez, J.M. and Navarro, M.V. (2002d). Moisture effects on the phenanthrene adsorption capacity by carbonaceous materials. Energy Fuels 16: 205-210.

Mastral, A.M., García, T., Murillo, R., Callén, M.S., López, J.M. and Navarro, M.V. (2003). Measurements of polycyclic aromatic hydrocarbon adsorption on activated carbons at very low concentrations. Ind. Eng. Chem. Res. 42: 155-161.

Mastral, A.M., García, T., Murillo, R., Callén, M.S., López, J.M. and Navarro, M.V. (2004). Development of efficient adsorbent materials for PAH cleaning from AFBC hot gas. Energy Fuels 18: 202-208.

McKay, G. (2002). Dioxin characterisation, formation and minimisation during municipal solid waste (MSW) incineration. Chem. Eng. J. 86: 343-368.

Mei, L., He, L., Fan, C.G., Hao, L.F., Li, S.G. and Song, W.L. (2014). Adsorption of naphthalene at low concentration on activated carbon. Chin. J. Process Eng. 14: 253-257.

Meier, W.M. and Siegmann, K. (1999). Significant reduction of carcinogenic compounds in tobacco smoke by the use of zeolite catalysts. Microporous Mesoporous Mater. 33: 307-310.

Meng, M.M., Liu, Y.S., Li, Z.Y., Jiang, L.J., Yang, X. and Liu, W.H. (2017). Adsorption characteristics of low concentration gaseous naphthalene on ordered mesoporous carbons. CIESC J. 68: 3109-3118.

Murillo, R., García, T., Aylón, E., Callén, M.S., Navarro, M.V., López, J.M. and Mastral, A.M. (2004). Adsorption of phenanthrene on activated carbons: Breakthrough curve modeling. Carbon 42: 2009-2017.

Okparanma, R.N. and Mouazen, A.M. (2013). Visible and near-infrared spectroscopy analysis of a polycyclic aromatic hydrocarbon in soils. Sci. World J. 2013: 160360.

Owabor, C.N., Ogbeide, S.E. and Susu, A.A. (2010). Adsorption and desorption kinetics of naphthalene, anthracene, and pyrene in soil matrix. Pet. Sci. Technol. 28: 504-2014.

Park, J.H. and Yang, R.T. (2005). Predicting adsorption isotherms of low-volatile compounds by temperature programmed desorption: Iodine on carbon. Langmuir 21: 5055-5060.

Perez-Maqueda, L.A., Criado, J.M., Gotor, F.J. and Malek, J. (2002). Advantages of combined kinetic analysis of experimental data obtained under any heating profile. $J$. Phys. Chem. A 106: 2862-2868

Ravenni, G., Sárossy, Z., Ahrenfeldt, J. and Henriksen, U.B. (2018). Activity of chars and activated carbons for removal and decomposition of tar model compounds-A review. Renewable Sustainable Energy Rev. 94: 10441056.

Ryoo, R., Joo, S.H. and Jun, S. (1999). Synthesis of highly ordered carbon molecular sieves via template-mediated structural transformation. J. Phys. Chem. B 103: 77437746.

Shie, J.L., Chang, C.Y., Chen, J.H., Tsai, W.T., Chen, Y.H., Chiou, C.S. and Chang, C.F. (2005). Catalytic oxidation of naphthalene using a $\mathrm{Pt} / \mathrm{Al}_{2} \mathrm{O}_{3}$ catalyst. Appl. Catal. B 58: 289-297.

Shiue, A., Hu, S.C., Tseng, C.H., Chuang, C.M. and Leggett, G. (2018). Assessment of adsorptive filter for removal of formaldehyde from indoor air. Aerosol Air Qual. Res. 18: 3147-3164.

$\mathrm{Su}$, Y.C., Kao, H.M. and Wang, J.L. (2010). Mesoporous silicate MCM-48 as an enrichment medium for ambient volatile organic compound analysis. J. Chromatogr. A 1217: 5643-5651.

Sugiyama, T., Shimada, K., Miura, K., Lin, N.H., Kim, Y.P., Chan, C.K., Takami, A. and Hatakeyama, S. (2017). Measurement of ambient PAHs in Kumamoto: Differentiating local and transboundary air pollution. Aerosol Air Qual. Res. 17: 3106-3118.

Todd, R.S. and Webley, P.A. (2002). Limitations of the LDF/equimolar counterdiffusion assumption for mass transport within porous adsorbent pellets. Chem. Eng. Sci. 57: 4227-4242.

Tsai, C.Y., Chiu, C.H., Chuang, M.W. and Hsi, H.C. (2017). Influences of copper(II) chloride impregnation on activated carbon for low-concentration elemental mercury adsorption from simulated coal combustion flue gas. Aerosol Air Qual. Res. 17: 1637-1648.

Tseng, H.H., Wey, M.Y., Chen, J.C. and Lu, C.Y. (2002). The adsorption of PAHs, BTEX, and heavy metals on surfactant-modified desulfurization sorbents in a dry scrubber. Fuel 81: 2407-2416.

Villemin, D., Cherqaoui, D. and Mesbah, A. (1994). Predicting carcinogenicity of polycyclic aromatic hydrocarbons from back-propagation neural network. $J$. Chem. Inf. Comput. Sci. 34: 1288-1293.

Vinu, A., Hossain, K.Z., Satish Kumar, G. and Ariga, K. 
(2006). Adsorption of L-histidine over mesoporous carbon molecular sieves. Carbon 44: 530-536.

Wang, K., Huang, B., Liu, D. and Ye, D. (2012). Ordered mesoporous carbons with various pore sizes: Preparation and naphthalene adsorption performance. $J$. Appl. Polym. Sci. 125: 3368-3375.

Wang, K., Zhao, J., Fu, M., Zhou, G., Huang, B. and Ye, D. (2013). Experimental and molecular simulation study for the preparation of ordered mesoporous carbons. Aerosol Air Qual. Res. 13: 1034-1044.

Wang, K., Fu, M., Wu, J., Zhou, G. and Ye, D. (2018). Computer simulation studies of structure characteristics of ordered mesoporous carbons and its naphthalene adsorption performance. Aerosol Air Qual. Res. 18: 542-548.

Wang, L.C., Lee, W.J., Tsai, P.J. and Chen, S.J. (2002). Potential method for reducing emissions of polycyclic aromatic hydrocarbons from the incineration of biological sludge for the terephthalic acid manufacturing industry. Environ. Sci. Technol. 36: 3420-3425.

Wang, L.C., Lin, L.F. and Lai, S.O. (2009). Emissions of polycyclic aromatic hydrocarbons from fluidized and fixed bed incinerators disposing petrochemical industrial biological sludge. J. Hazard. Mater. 168: 438-444.

Xi, H.X., Li, Z. and Zhang, H.B. (2003). Estimation of activated energy and isotherm of low-volatility dioxin by TPD technique. Sep. Purif. Technol. 31: 39-43.

Xue, H.B. (2011). Study on adsorption and desorption behaviors of PAHs on granular activated carbon. Master's thesis, Nanjing University of Information Science \& Technology, Nanjing, China.

Yang, K., Wu, W., Jing, Q. and Zhu, L. (2008). Aqueous adsorption of aniline, phenol, and their substitutes by multi-walled carbon nanotubes. Environ. Sci. Technol. 42: 7931-7936.

Yang, Q., Liu, Y.S., Li, Z.Y., Yang, X., Wang, Z.Y., Jiang, L.J. (2015). Study on the adsorption behaviours of naphthalene on MCM-41 and SBA-15 mesoporous molecular sieves. J. Fuel Chem. Technol. 43: 1482-1488.

Yang, X., Zhang, C., Jiang, L., Li, Z., Liu, Y., Wang, H., Xing, Y. and Yang, T.R. (2019). Molecular simulation of naphthalene, phenanthrene, and pyrene adsorption on MCM-41. Int. J. Mol. Sci. 20: 665.

Yong, G.P., Jin, Z.X., Tong, H.W., Yan, X.Y., Li, G.S. and Liu, S.M. (2006). Selective reduction of bulky polycyclic aromatic hydrocarbons from mainstream smoke of cigarettes by mesoporous materials. Microporous Mesoporous Mater. 91: 238-243.

Yu, L., Tu, X., Li, X., Wang, Y., Chi, Y. and Yan, J. (2010). Destruction of acenaphthene, fluorene, anthracene and pyrene by a dc gliding arc plasma reactor. $J$.
Hazard. Mater. 180: 449-455.

Zeng, W. and Bai, H. (2016). Adsorption/desorption behaviors of acetone over micro-/mesoporous SBA-16 silicas prepared from rice husk agricultural waste. Aerosol Air Qual. Res. 16: 2267-2277.

Zhang, L., Li, P., Gong, Z. and Li, X. (2008). Photocatalytic degradation of polycyclic aromatic hydrocarbons on soil surfaces using $\mathrm{TiO}_{2}$ under UV light. J. Hazard. Mater. 158: 478-484.

Zhang, N., Cao, J., Li, L., Ho, S.S.H., Wang, Q., Zhu, C. and Wang, L. (2018). Characteristics and source identification of polycyclic aromatic hydrocarbons and $n$-alkanes in $\mathrm{PM}_{2.5}$ in Xiamen. Aerosol Air Qual. Res. 18: $1673-1683$.

Zhao, D., Feng, J., Huo, Q., Melosh, N., Fredrickson, G.H., Chmelka, B.F. and Stucky, G.D. (1998). Triblock copolymer syntheses of mesoporous silica with periodic 50 to 300 angstrom pores. Science 279: 548-552.

Zhong, Z., Jin, B., Huang, Y., Zhou, H. and Zhang, M. (2008). Experimental study on flue gas purifying of MSW incineration using in-pipe jet adsorption techniques. Waste Manage. 28: 1923-1932.

Zhou, H.C., Zhong, Z.P., Jin, B.S., Huang, Y.J. and Xiao, R. (2005). Experimental study on the removal of PAHs using in-duct activated carbon injection. Chemosphere 59: 861-869.

Zhou, H.C., Cai, H.X., Xue, H.B., Song, Y.Y., Zhang, C.C. and Lu, J.G. (2010a). Static adsorption mechanism of naphthalene on carbonaceous sorbents. Res. Environ. Sci. 23: 658-662. (in Chinese with English Abstract)

Zhou, H.C., Xue, H.B., Zhang, C.C., Cai, H.X., Xiao, X. and Xie, W.J. (2010b). Desorption kinetics of naphthalene and acenaphthene on activated carbon. Proc. CSEE 30: 35-40.

Zhou, S.L., Wang, Y., Xu, J.H., Xu, Y., Cao, Y., Zhu, J.H., He, X.W., Zhang, Y. and Wang, H. (2004). Removing polycyclic aromatic hydrocarbons and nitrosamines in cigarette smoke by use of material with nano-porous structures. Jiangsu Chem. Ind. 32: 29-31. (in Chinese with English Abstract)

Zhou, S.L., Lv, J., Xu H.T., Yue, Y., Sheng, Z.Y., Hu, S.L., Liang, S., Xiao, X.Z., Wang, Y., Yun, Z.Y., Cao, Y. and Zhu, J.H. (2008). The mechanism of micropore zeolites removing polycyclic aromatic hydrocarbons in cigarette smoke. Acta Tabacaria Sinica 14: 1-6. (in Chinese with English Abstract)

Received for review, November 4, 2018 Revised, March 7, 2019 Accepted, March 8, 2019 